\title{
AC 2011-148: PROGRAM FOR STUDENT RETENTION AND SUCCESS IN ENGINEERING
}

\section{Rafic Bachnak, Texas A\&M International University}

Dr. Bachnak is a Professor at Texas A\&M International University (TAMIU). He received his B.S., M.S., and Ph.D. degrees in Electrical from Ohio University in 1983, 1984, and 1989, respectively. Prior to joining TAMIU in 2007, Dr. Bachnak was on the faculty of Texas A\&M-Corpus Christi, Northwestern State University, and Franklin University. His experience includes several fellowships with NASA and the US Navy Laboratories and employment with Koch Industries. Dr. Bachnak is a registered Professional Engineer in the State of Texas, a senior member of IEEE and ISA, and a member of ASEE. During the 2009-2010 academic year, he was a Fulbright Scholar at Notre Dame University, Lebanon.

\section{Runchang Lin, Texas A\&M International University}

Dr. Runchang Lin received Ph.D. in Mathematics and M.A. in Statistics from Wayne State University, Detroit, MI, and M.S. in Computational Mathematics and B.S. in Mathematics from Tongji University, Shanghai, China. He is an Assistant Professor of Mathematics at Texas A\&M International University, Laredo, TX and has been a Visiting Assistant Professor at Purdue University, West Lafayette, IN in Spring 2009. Dr. Lin's research interest is in Numerical Analysis and Applied Mathematics. He has published 17 articles in numerical analysis and education in peer reviewed journals.

\section{Rohitha Goonatilake, Texas A\&M International University}

Dr. Rohitha Goonatilake, Associate Professor of Mathematics, holds a Ph.D. in applied mathematics (Dec. 1997) from Kent State University, Kent, Ohio. Dr. Goonatilake severs as a PI for several grants, including NSF South Texas Border Mathematics and Pre-Engineering Graduates CSEMS scholarships program from 2006-2008 and Texas Higher Education Coordinating Board and Texas Education Agency Teacher Quality Higher Education Type B Grants Program under No Child Left Behind Act from 20052006. He is also a member of American Mathematical Society, Mathematical Association of America, Institute of Mathematical Statistics, and an invited member of The Honor Society of Phi Kappa Phi. He has several articles in peer review journals including The Proceedings of American Mathematical Society, Southwest Journal of Pure and Applied Mathematics, and Journal of Applied Mathematics and Stochastic Analysis. His main areas of research are Probability Theory and Analysis. 


\title{
Program for Student Retention and Success in Engineering
}

\begin{abstract}
The world is facing challenges that require a highly-skilled and creative engineering workforce. This paper describes a program that improves the recruitment and retention of highly motivated minority students into engineering disciplines. The program involves recruiting a Pre-Engineering Cohort that participates in a number of enrichment activities, including a Summer Transfer Workshop. The workshop introduces cohort participants to the engineering degree programs offered by Dwight Look College of Engineering at Texas A\&M University (TAMU). Participants live in campus residence halls and interact with department faculty, staff and students through several activities, including information sessions, field trips, laboratory tours, and design projects. While students are exposed to the various engineering fields, they also improve their critical thinking and problem solving skills. This paper presents details about the 2009 and 2010 workshops.
\end{abstract}

\section{Introduction}

According to the U.S. Bureau of Labor Statistics, 15 of the 20 fastest-growing occupations projected through 2010 and beyond will require substantial mathematics or science skills. Furthermore, it is estimated that the number of young adults 18 to 24 years was projected to grow by 3 million between 2000 and 2010. Of these young adults 56 percent are minority students who are underrepresented in higher level mathematics and science classes in high school and college. Also, Hispanics are seriously underrepresented in higher education programs and the degree of underrepresentation increases as the level of education increases. This generalization holds true for Hispanic graduates in higher education science and engineering programs. The data for Hispanic graduates from science and engineering programs shows the situation needs to be corrected right away [1]. Therefore, many initiatives are focusing on minority populations in order to sustain engineering education and address the rapid industrialization, economic development, and innovations that are taking place in the world.

Strategies employed to recruit and retain students in engineering include a variety of approaches, such as hands-on activities, summer workshops, competitions, research experiences, and preengineering programs [2-6]. This paper describes a recruitment and retention program that is designed to increase the number of minority students in engineering by forming Pre-Engineering Cohorts (PE-Cohort) that participates in a number of enrichment activities, including a Summer Transfer Engineering Workshop (STEW). STEW is a two week residential program that introduces TAMIU pre-engineering students to the engineering degree programs offered by the Dwight Look College of Engineering at Texas A\&M University (TAMU), College Station, Texas. Participants live in campus residence halls during the program and interact with department faculty, staff and students through several activities, including information sessions, field trips, laboratory tours, and design projects. While students are exposed to the various engineering fields, they also improve their critical thinking and problem solving skills. The following pages present details about the 2009 and 2010 cohorts and briefly discuss the results. 


\section{Engineering at TAMIU}

TAMIU currently has a pre-engineering program and a bachelors’ degree in systems engineering. The pre-engineering program facilitates the automatic admission and academic transfer of students from TAMIU into engineering degree programs at TAMU. This arrangement allows students to take the first two years of core and engineering courses at TAMIU and be admitted to the engineering program of their choice at TAMU. In order to qualify, students must complete a minimum of 42 credits from a degree plan, including required courses, maintain a minimum 3.0 GPA and meet all other general transfer admission requirements. This opportunity makes it possible for local students to have access to one of the best engineering programs in the world. Enrollment history of engineering students at TAMIU is shown in Table 1.

Table 1: Enrollment history of engineering students by years

\begin{tabular}{|c|c|c|}
\hline Semester & Program & Number of Students \\
\hline \multirow{2}{*}{ Fall 2007 } & Pre-Engineering & 34 \\
\cline { 2 - 3 } & Systems Engineering & 0 (Program did not exit) \\
\hline \multirow{2}{*}{ Fall 2008 } & Pre-Engineering & 33 \\
\cline { 2 - 3 } & Systems Engineering & 5 \\
\hline \multirow{2}{*}{ Fall 2009 } & Pre-Engineering & 44 \\
\cline { 2 - 3 } & Systems Engineering & 10 \\
\hline \multirow{2}{*}{ Fall 2010 } & Pre-Engineering & 118 \\
\cline { 2 - 3 } & Systems Engineering & 54 \\
\hline
\end{tabular}

Table 2 shows the growth of engineering enrollment at TAMIU and provides ethnicity and gender information.

Table 2: Engineering student enrollment by ethnicity and gender

\begin{tabular}{|c|c|c|c|c|c|}
\hline \multirow{2}{*}{ Semester } & \multirow{2}{*}{$\begin{array}{c}\text { Total Number } \\
\text { of Students }\end{array}$} & \multicolumn{2}{|c|}{ Ethnicity } & \multicolumn{2}{c|}{ Gender } \\
\cline { 3 - 6 } & 34 & Hispanic & Non-Hispanics & Males & Females \\
\hline Fall 2007 & $38(97 \%)$ & $1(3 \%)$ & $30(88 \%)$ & $4(12 \%)$ \\
\hline Fall 2008 & 54 & $32(97 \%)$ & $1(3 \%)$ & $33(87 \%)$ & $5(13 \%)$ \\
\hline Fall 2009 & 174 & $51(94 \%)$ & $3(6 \%)$ & $44(81 \%)$ & $10(19 \%)$ \\
\hline Fall 2010 & $151(87 \%)$ & $23(13 \%)$ & $149(86 \%)$ & $25(14 \%)$ \\
\hline
\end{tabular}

Engineers need to be innovative and should have a mindset that allows them to carry the field of technology into the new decade. This strategy should be implemented to modify the way students think. The engineering faculty needs to leave behind the traditional way of teaching and start creating the building blocks for the future innovation. By getting students to think of themselves as entrepreneurs instead of just workers, the outlook of engineering could be promising and rewarding. The last cause that should be addressed to make sure that engineering graduates know what exactly it means for them to practice engineering throughout the real world. The university faculty need to instill not only book smarts, but also working under time constraints, correcting problems without assistance, dealing with the increasing amount of political pressures, ethical training, and understanding their obligation to the general public as professional engineers. Each course should have its own practical contents in place to help students grow in each one of these categories and help them become well-rounded graduates. Due to this, it is only natural for the educational process and for the students themselves to change along with it. These ideas help improve not only the education but the future technologies of engineering as well $[6,7]$. 
TAMIU is addressing these needs by forming PE-Cohorts that are supported by funds from the STEM Recruitment, Retention, and Graduation (STEM RRG) project, funded by the U.S. Department of Education [8, 9]. Activities were completed in three different stages: (1) Recruit students and provide the theme of the program, (2) Provide a series of enrichment activities, including advising and faculty mentoring, and (3) Participate in STEW at TAMU. In the following sections, we discuss planning of this program, transfer activities undertaken, results, and feedback received from the students.

\section{Summer Transfer Workshop}

The flyer and application materials were distributed to all incoming freshman students enrolled in pre-engineering and B.S. Degree Program in Systems Engineering by late 2008. All applicants were asked to submit a 200 to 300 word typed essay describing their educational goals and career plans. This became the focus of consideration for their applications being selected. Twenty-one applications were chosen to form the cohort. They were provided with academic counseling, advising, and mentoring through out the academic year.

During the first week of the program through a series of meetings, students were told what was expected from them while they were in the cohort. They signed-up to become members of the Society of Engineering at TAMIU (SET), thus participating in activities such as fundraising and picnics. All participants attended the Department of Engineering, Mathematics, and Physics colloquium talks. There are roughly 8-10 talks every year by faculty and invited speakers at these events. A laptop was provided to each participant to conduct research and use during their college years. They were also given the opportunity to conduct research in computer science, mathematics, physics, or engineering. Several participants presented at the Department Fall Student Conference held on November 6, 2009 and The 2009 Lamar Bruni Vergara Academic University Conference held on April 20-24, 2009 held at TAMIU, respectively. The first STEW was offered to a group of 19 TAMIU students, including one female, on the campus of TAMU from July $19^{\text {th }}$ through July $31^{\text {st }}$, 2009. Students lived on campus in Lechner Hall, giving them a glimpse of what life would be like at TAMU, along with a taste of campus cuisine. The two-week schedule included the following activities:

- Tours and demonstrations of engineering laboratories and facilities

- Discussions with industry representatives and faculty members

- Presentations about the future trends in different engineering disciplines and the career options for students

- Work on an interdisciplinary design project such as robot's programming and building engineering structures

- Field trip to an engineering company

A list of engineering departments that that participated in offering activities follows:

- Aerospace Engineering

- Biological \& Agricultural Engineering

- Computer Science \& Engineering

- Nuclear Engineering

- Biomedical Engineering 
- Petroleum Engineering

- Industrial Systems Engineering

- Electrical \& Computer Engineering

- Chemical Engineering

- Civil Engineering

- Mechanical Engineering

- Eng Technology \& Industrial Distribution

Highlights of the 2009 STEW included hands-on design projects, flight simulation, rocket launching, robotics demonstrations, sketch recognition, tour of the nuclear reactor, bioenergy and biofuel demonstrations, and virtual design. These activities offered them interaction with faculty members and gave them a clear idea of what is expected of them in the different disciplines. Participants had nothing but appreciation for all activities. There was a weak female participation as shown in Table 3.

Table 3: Student participation in the PE cohort by gender

\begin{tabular}{|c|c|c|c|}
\hline & Male & Female & All Students \\
\hline TAMIU Students & 18 & 1 & 19 \\
\hline
\end{tabular}

After their return from TAMU, STEW participants were asked to attend a mentor session and complete a feedback form. During this session, a number of issues were discussed, including GPA requirements, transfer requirements, experience of the STEW workshop, and feedback to help plan next year's program. 2009 STEW participants had mostly positive things to say about their two week experience. Their comments included: "It was a great experience, and we had excellent accommodations, excellent educational experience; there were wonderful people, and it was a wonderful city." "The days were long, leaving the dorms at 7:00 am and returning at 6:00 pm, but the time was spent very well." "The hands-on experience with each department and facility that TAMU had for us was very educational." "Wonderful job, excellent food, older facilities but that didn't matter." "The dorms were nice; the only problem is that we could not obtain internet in our rooms.”

Students completed a survey consisting of the following questions:

1. The orientation program I received was well organized and well delivered.

2. The orientation program provided was helpful and informative.

3. The orientation environment was inviting, comfortable, and adequately designed.

4. The length and speakers of the orientation program were appropriate.

5. The orientation program provided me with a greater understanding of my career goals and expectations of engineering profession.

6. In your opinion, how could the orientation program provided by the STEM-RRG program be improved to achieve the goals and expectations of the program?

7. In your opinion, how could the orientation provided by the STEM-RRG program can be beneficial to you?

8. Is there additional information that you feel you needed to receive to better prepare you to achieve the objectives of the PE Cohort?

9. Any additional comments that you think will be helpful to the organizers of the workshop.

Results to questions 1 thru 5 of the Feedback Form are summarized in Figure 1. Note the 1-5 scale, with 1-strongly agree, 2-agree, 3-neutral, 4-disagree, 5-strongly disagree. 


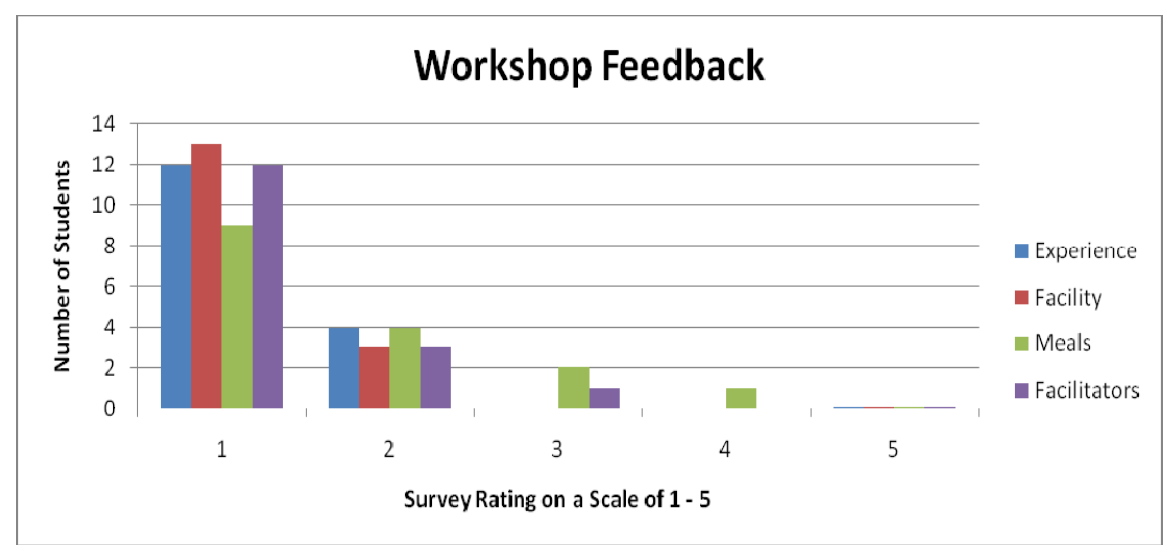

Figure 1: Summary of responses on the feedback form

Students were asked if they would change anything about the workshop format. Besides their suggestion to fix the wireless internet problem, many students would not have changed a thing. One student offered this piece of advice, "Two weeks is enough time to explore each engineering field; maybe each student should spend more time on the branch of engineering that interests them." The majority of the students agree that the workshop was beneficial to their engineering education and in providing guidance into what field of engineering they are most interested in. Another student said, "The days were long, leaving the dorms at 7:00 am and returning at 6:00 pm, but the time was spent very well.” When the students were asked what parts of the workshop had the most impact on them, the responses varied. Some students enjoyed the Civil Engineering component; others liked the Industrial and Mechanical Engineering topics. Another student responded by saying, "The hands-on experience with each department and facility that TAMU had for us were very educational."

Students were also asked about the food and the facilities, their responses were mixed. “Wonderful job, excellent food, older facilities but that didn't matter." Others, however, said, "The dorms were nice; the only problem is that we could not obtain internet in our rooms." The lack of wireless internet in the dorm rooms seemed to be a problem with many of the workshop participants. The students were also asked to rate the workshop staff. However, the majority of participants have expressed their greater appreciation towards workshop experience.

\section{Summer Transfer Workshop}

This is the second STEW offered to TAMIU students. This year a group of twenty four students, including three female students, participated in the workshop held from July 25th through August 6th, 2010 on the campus of TAMU. The two-week schedule included the following activities:

Tours and demonstrations of engineering laboratories and facilities

Discussions with industry representatives, faculty members, and TAMU students Presentations about the future trends in different engineering disciplines and the career options for students Work on an interdisciplinary design projects such as electronic game design, robot's programming, and engineering structures design 
All engineering departments of TAMU, including Aerospace Engineering, Biological \& Agricultural Engineering, Biomedical Engineering, Chemical Engineering, Civil Engineering, Computer Science \& Engineering, Electrical \& Computer Engineering, Engineering Technology \& Industrial Distribution, Industrial and Systems Engineering, Mechanical Engineering, Nuclear Engineering, and Petroleum Engineering, participated in 2010.

Highlights of the 2010 STEW included hands-on design projects, flight simulation, rocket launching, robotics demonstrations, sketch recognition, bioenergy and biofuel demonstrations, water-wheel design, and virtual design. These activities offered them interaction with faculty members and gave them a clear idea of what is expected of them in the different engineering disciplines. Table 4 shows improvement of female participantion in the 2010 cohort.

Table 4: Student participation in the PE-Cohort

\begin{tabular}{|l|c|c|c|}
\hline & Male & Female & All Students \\
\hline 2009 PE-Cohort Participants & 18 & 1 & 19 \\
\hline 2010 PE-Cohort Participants & 21 & 3 & 24 \\
\hline
\end{tabular}

\section{Conclusion}

The summer 2009 STEW served 19 students, including one female. The 2010 workshop served 24 students, including 3 females. Both workshops were highly rated by participants. Students who maintain a GPA of 3.0 or higher, are eligible for automatic transfer if they choose to go to TAMU. About one third the STEW participants are staying at TAMIU to pursue a degree in Systems Engineering. While this program offers a practical approach to address the expected shortage in engineering graduates, it also promotes STEM education.

\section{Acknowledgement}

The Pre-Engineering Cohort project is partially supported by STEM Recruitment, Retention, and Graduation (STEM RRG), a project funded by the U.S. Department of Education (Award \# P031C080083). More information about this grant is found at http://www.tamiu.edu/ rbachnak/STEMRRG/index3.html.

\section{Bibliography}

[1] Jorge Chapa and Belinda De La Rosa (2006), “The Problematic Pipeline Demographic Trends and Latino Participation in Graduate Science, Technology, Engineering, and Mathematics Programs,” Journal of Hispanic Higher Education, Vol. 5, No. 3, pp. 203-221.

[2] David Keathy, Robert Akl, Ryan Garlick, “Attracting and retaining women in computer science and engineering,” Proceeeings of the American Society for Engineering Education Annual Conference, 2007.

[3] Quamrul Mazumder, Olanrewaju Aluko, “A pre-engineering program to motivate high school students towards engineering, Proceeeings of the American Society for Engineering Education Annual Conference, 2010.

[4] Jon J. Kellar, Wendell Hovey, Michael Langerman, Stan Howard, Larry Simonson et al. (2000), “A Problem Based Learning Approach for Freshman Engineering,” 30th ASEE/IEEE Frontiers in Education Conference, October 18 - 21, 2000, Kansas City, MO.

[5] Daryl E. Chubin, Gary S. May, and Eleanor L. Babco (2005), “Diversifying the Engineering Workforce,” Journal of Engineering Education, Vol. 94, No. 1, pp. 73-86.

[6] C. Dym, A. Agogino,O. Eris, D. Frey, and L. Leifer, (2005), “Engineering Design Thinking, Teaching, and Learning,” Journal of Engineering Education, Vol. 94, No. 1, pp. 103-120 
[7] Wayne Clough (2000), “The Future of Engineering Education,” Stay Informed! Magazine, http://gtalumni.org/Publications/magazine/win00/future.html

[8] STEM-RRG Program: http://www.tamiu.edu/ rbachnak/STEMRRG/index3.html

[9] Rafic A. Bachnak, Rohitha Goonatilake, Tongdan Jin, and Fethi Belkhouche, “A Glimpse of An Effective Cohort Program for Undergraduate Students to Promote Engineering”, International Journal of Engineering Studies (IJES), Vo. 2, No. 1, 2010, pp. 59-66. 